\title{
Measuring Intraspecific Variation in Flight-Related Morphology of Monarch Butterflies (Danaus plexippus): Which Sex Has the Best Flying Gear?
}

\author{
Andrew K. Davis and Michael T. Holden \\ Odum School of Ecology, University of Georgia, Athens, GA 30602, USA \\ Correspondence should be addressed to Andrew K. Davis; akdavis@uga.edu
}

Received 11 August 2015; Accepted 12 October 2015

Academic Editor: Yuxian Xia

Copyright (C) 2015 A. K. Davis and M. T. Holden. This is an open access article distributed under the Creative Commons Attribution License, which permits unrestricted use, distribution, and reproduction in any medium, provided the original work is properly cited.

Optimal flight in butterflies depends on structural features of the wings and body, including wing size, flight muscle size, and wing loading. Arguably, there is no butterfly for which flight is more important than the monarch (Danaus plexippus), which undergoes long-distance migrations in North America. We examined morphological features of monarchs that would explain the apparent higher migratory success and flight ability of females over males. We examined 47 male and 45 female monarch specimens from a project where monarchs were reared under uniform conditions. We weighed individual body parts, including the thorax (flight muscle) and wings, and computed wing loading and wing thickness for all specimens. When we compared each morphological trait between sexes, we found that females did not differ from males in terms of relative thorax (wing muscle) size. Females were generally smaller than males, but females had relatively thicker wings than males for their size, which suggests greater mechanical strength. Importantly, females had significantly lower wing loading than males ( $7 \%$ lower). This would translate to more efficient flight, which may explain their higher migratory success. Results of this work should be useful for interpreting flight behavior and/or migration success in this and other Lepidopteran species.

\section{Introduction}

While flight is undoubtedly a key characteristic of all Lepidoptera, there is arguably no other species within this order which relies as heavily on flight performance as the monarch butterfly (Danaus plexippus). Monarchs in North America undergo long-distance seasonal migrations to and from overwintering sites in coastal California and central Mexico $[1,2]$. The population east of the Rocky Mountains that travels to Mexico from breeding areas in Canada and the northern United States has one of the longest migrations of any insect species, and for these butterflies, optimal flight would be critical for successfully making this journey. Work with other butterfly species has shown how flight performance is largely determined by specific morphological traits, including the size and shape of wings, the size of flight muscles, and the degree of wing loading (e.g., [3-5]). However, despite the known importance of flight to monarch butterflies, few studies have directly examined flight-related traits of monarchs to ask even the most basic questions, such as do male and female monarchs differ in flight-related morphology?

The question of gender differences in flight-related morphology within monarchs is timely because evidence is now accumulating that suggests female monarchs may have superior flight ability and migratory success over males. First, in a series of flight mill trials using captive monarchs, females were found to fly significantly longer and farther than males [6]. Second, data from two independent tagging projects during the fall migration in eastern North America show how female monarchs tend to have higher recovery rates at the Mexican overwintering sites than do males; in Pennsylvania, where over 11,000 monarchs had been tagged over 18 years, the recovery rate of females was significantly higher than of males [7], and Brindza et al. [8] also showed females were more likely to be recovered from monarchs tagged in Virginia. Third, data from a multiyear tagging project in South Carolina showed that female monarchs were half 
as likely to stop and stay at this site as males (even after accounting for differing capture frequencies, [9]), suggesting females may require less frequent stopovers during the migratory journey. In fact, this last conclusion can also be inferred from overall capture frequencies of males versus females during migration; at most fall tagging sites, less than $40 \%$ (sometimes less than $30 \%$ ) of captured monarchs are female $[7,8,10]$. This does not appear to be from sex-related behavioral differences at stopover sites [11], so the inference is that females appear to stop less frequently than do males during migration.

The potential mechanism by which female monarchs achieve higher flight ability and/or migration success is not clear. Male and female monarchs do not differ in terms of overall wing shape $[12,13]$, which is an important trait for monarch migration [13] and for overall flight performance in other butterflies [3]. There is also no evidence that lipid accumulation of males and females differs during migration [1416]. One possible explanation could be that males and females have inherent differences in flight-related morphology, such as flight muscle size or wing loading (i.e., mass of butterfly in relation to wing size), and testing this idea was the primary goal of the current study.

Here we report results of a descriptive study of the finescale wing and body morphology of monarch butterflies, which we conducted to uncover patterns that would explain the apparent sex-related differences in flight ability in this species. We specifically tested the prediction that female monarchs would have superior flight-related traits than male monarchs. These traits included overall size, flight muscle size, relative wing thickness, and wing loading. Results from this effort should be useful for interpreting the gender bias seen within the migratory generation and the differences in recovery rates at the overwintering sites and, more generally, will improve scientific knowledge surrounding this, the world's most famous butterfly.

\section{Methods}

2.1. Butterfly Specimens. All specimens used in this project originated from a separate and unrelated experiment conducted in 2005, in which a collection of monarchs (from the eastern North American population) was reared in captivity to examine fitness consequences of infection with Ophryocystis elektroscirrha [17]. Both infected and uninfected monarchs were reared, but for the purposes of this project, we only used the uninfected monarchs from this collection. Each monarch larva in that project had been reared individually in 1 liter plastic containers and fed greenhouse-grown milkweed (Asclepias incarnata) until pupation. Upon eclosion, all adults were weighed, their sex was recorded, and then they were placed in glassine envelopes and stored at $12^{\circ} \mathrm{C}$ until death; this is to measure adult longevity, which is an important metric of butterfly fitness $[18,19]$.

2.2. Scanning and Measuring Wings. At the conclusion of the experiment above, the fore- and hindwings of each specimen had been removed and scanned, dorsal side down, on a

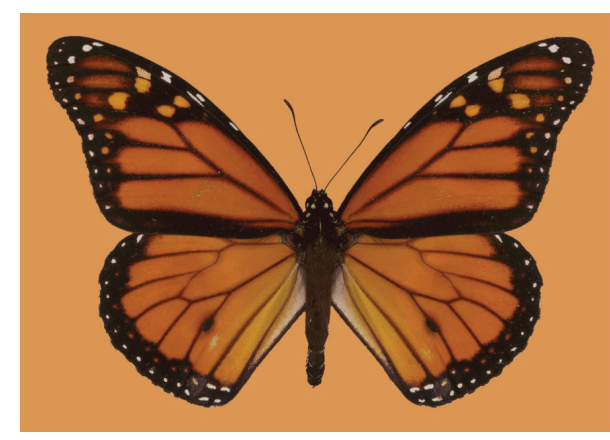

(a)

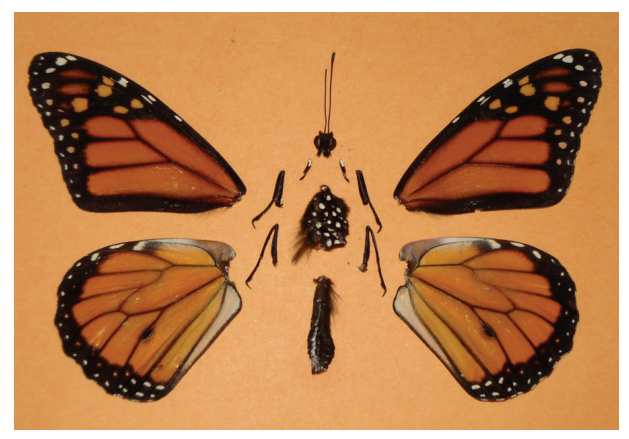

(b)

FIGURE 1: (a) Male monarch butterfly, Danaus plexippus. (b) Monarch with individual body parts isolated prior to weighing.

flatbed scanner following Davis et al. [6,20]. This produces a digital version of the wings which can then be measured in minute detail using image analysis software [21, 22]. Each image was then imported into an image analysis package (FoveaPro, http://www.reindeergraphics.com/), and we measured the surface area of the forewings and hindwings. At the conclusion of this project, all specimens were stored at $-20^{\circ} \mathrm{C}$.

2.3. Weighing Monarchs. During fall of 2013, all monarch specimens from the project above were removed from cold storage for the current investigation. Each specimen was weighed whole to obtain a dry weight (the wings had already been removed from the body for scanning but were included in this weight measurement). Note that we did not dry the specimens in an oven for these weights, but since they had been in cold storage for 8 years, we assumed the specimens were mostly dry. This assumption means that values obtained here relating to mass may not be consistent with those obtained after oven-drying of specimens, but here we were only concerned with the relative differences among individuals of this collection. Then one of us $(\mathrm{MH})$ carefully dissected the specimen to separate out the individual body parts (Figure 1). This included removing the head and legs, isolating the thorax as well as the abdomen (including removal of legs). Then, we used a high-precision digital scale to individually weigh each body part. A total of 92 healthy monarchs ( 47 males, 45 females) were measured. 
2.4. Flight Performance Traits. Flight muscle size is an important predictor of flight ability in butterflies, and since these muscles are completely contained in the thorax [23], most researchers consider the thorax (excluding legs) mass as a proxy for wing muscle size [24-27]. Since thorax size varies allometrically with whole-body size in butterflies (in our data, thorax mass was highly correlated with dry specimen mass, $r=0.95, p<0.0001$ ), we computed the relative thorax size (mass of thorax/dry specimen mass $* 100$ ) to use for analysis. Relative wing thickness, an index of mechanical strength (i.e., flexural stiffness) of butterfly wings [28], was computed by dividing the average forewing weight by the average forewing area, following Steppan [28]. Wing loading was computed by dividing specimen wet mass by total wing surface area, following Byrne et al. [29].

2.5. Data Analyses. The complete data set for this project included all wing size data from the scanned images, as well as the weights of all body parts and the computed variables outlined above. These variables were all normally distributed based on visual inspection of their distributions. For the current investigation we were interested in knowing if male and female monarchs differed in any of the morphological traits that influence flight performance. We therefore used Student's $t$-tests to compare each variable between sexes. All analyses were conducted using the Statistica 6.1 software package (StatSoft, Tulsa, USA).

\section{Results}

The mean values of all morphological characteristics measured in this study, including the wing dimensions measured from image analysis of wings, and the weights of individual body parts, are shown in Table 1. Comparisons of these means between sexes (Student's $t$-tests) indicated males had significantly larger total wing surface area $(p=0.024)$ than females and were significantly heavier than females at eclosion (live weight, $p<0.0001$ ) and when dry weights of specimens were considered $(p<0.001)$. Males had heavier thoraxes than females $(p<0.0001)$ and their thoraxes were also larger relative to the whole specimen size $(p<0.001)$. Considering both sexes together, the thorax mass accounted for approximately $35 \%$ of the dry mass of the butterfly. This is comparable to that found in migrating monarchs in the fall (e.g., 30\%, [16]).

Male and female monarchs differed significantly in their wing loading scores $(p<0.0001$; Table 1$)$; females had lower average wing loading estimates than males. Based on the mean values shown in Table 1, we estimate the magnitude of this difference to be close to $7 \%$. The sexes also differed in relative wing thickness $(p<0.001)$, with females having thicker wings on average. We estimate this difference to be approximately $4 \%$.

\section{Discussion}

Results of this project represent the first detailed description of the flight-related characteristics of monarch butterflies,
TABLE 1: Summary of morphological characteristics of male $(n=$ $47)$ and female $(n=45)$ monarch butterflies from this study. All monarchs were reared in captivity under uniform conditions and fed greenhouse-grown milkweed. The table shows means with standard deviations in parentheses. Asterisks indicate significant differences between sexes based on Student's $t$-tests.

\begin{tabular}{lccc}
\hline Variable & Males & Females & Both sexes \\
\hline $\begin{array}{l}\text { Total wing area } \\
\left(\mathrm{mm}^{2}\right)\end{array}$ & $3387(222)^{*}$ & $3284(212)$ & $3336(222)$ \\
$\begin{array}{l}\text { Forewing area } \\
\left(\mathrm{mm}^{2}\right)\end{array}$ & $856(54)$ & $835(55)$ & $846(55)$ \\
$\begin{array}{l}\text { Monarch live wt } \\
(\mathrm{mg})\end{array}$ & $588(51)^{* * *}$ & $531(49)$ & $560(57)$ \\
$\begin{array}{l}\text { Monarch dry wt } \\
(\mathrm{mg})\end{array}$ & $162(15)^{* *}$ & $154(14)$ & $158(15)$ \\
$\begin{array}{l}\text { Thorax dry wt } \\
(\mathrm{mg})\end{array}$ & $57(6)^{* * *}$ & $53(6)$ & $55(6)$ \\
$\begin{array}{l}\text { Relative thorax } \\
\text { size }(\%)\end{array}$ & $35.4(1)^{* *}$ & $34.5(1)$ & $34.9(1)$ \\
$\begin{array}{l}\text { Abdomen dry } \\
\text { wt (mg) }\end{array}$ & $48(5)$ & $46(5)$ & $47(5)$ \\
$\begin{array}{l}\text { One forewing } \\
\text { dry wt }(\mathrm{mg})\end{array}$ & $12(1)$ & $12(1)$ & $12(1)$ \\
$\begin{array}{l}\text { Wing loading } \\
\left.(\mathrm{mg} / \mathrm{mm})^{2}\right)\end{array}$ & $.173(.009)^{* * *}$ & $.161(.009)$ & $.168(.011)$ \\
$\begin{array}{l}\text { Relative } \\
\text { forewing wt } \\
\left(\mathrm{mg} / \mathrm{mm}{ }^{2}\right)\end{array}$ & $.0136(.0009)^{* *}$ & $.0142(.0007)$ & $.0139(.0009)$ \\
\hline$* * * p<0.0001, * * p<0.001$, and $^{*} p<0.05$. &
\end{tabular}

and there were particular patterns found here that were both surprising and novel within the body of literature surrounding this butterfly. A case in point was with our assessment of flight muscle (i.e., thorax) sizes of male and female monarchs. Contrary to our hypothesis, females did not have larger flight muscles than males. This result is paradoxical because their wings appear to be proportionally heavier than are male wings (heavier wings should lead to larger, not smaller, flight muscles). The key element to this puzzle may lie in the mating behavior of monarch butterflies; after successful pairing, males carry the females for up to 18 hours [30]. This behavior may require extensive investment into flight muscle development, so male flight muscles may simply be larger than females because of this behavior [31].

Of the computed flight performance parameters, wing loading is perhaps the most critical, and here we found a key difference between male and female monarchs that may help explain their different migration success rates; female wing loading was significantly lower than that of males (about 7\% lower). Wing loading scores are indicative of how much work the wings must perform to carry the weight of the insect, and lower wing loading means it would take less energy to fly [32-34]. This pattern may explain both the higher success rates of female monarchs over males in reaching the overwintering sites $[7,8]$ and the longer flight times of females over males in captive flight mill studies [6]. These results are also consistent with prior assessments of body 

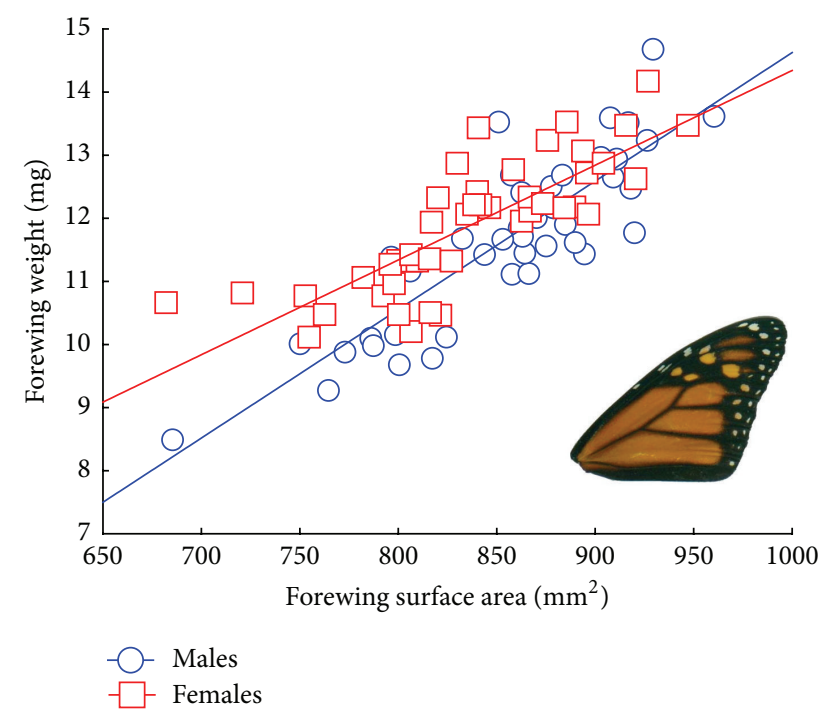

FIGURE 2: Relationship between forewing surface area and mass for monarch butterflies in this study. Note that female monarch wings tend to be heavier than males for their size, indicating greater relative wing thickness.

and wing size in monarchs, which found that females tend to have smaller bodies than males [13]. Similar comparisons of male and female morphology within other Lepidoptera species have shown varied results, with females tending to have lower wing loading in some cases [35], but not in others [36-38].

A surprising difference we found between male and female morphology was in their relative wing thickness: based on our estimates of this parameter, female monarchs tended to have relatively thicker wings, despite their smaller body sizes. The sex-based differences in relative wing thickness can also be visualized in a plot of forewing area versus forewing mass (Figure 2). For any given wing size (area) along the $x$-axis of this graph, note that female wings were usually heavier than males. This means that female wings must be thicker and/or denser in structure than for males. We interpret this to mean that female wings are generally sturdier and more robust (i.e., less included to break), although this idea may have to be experimentally verified by measuring their flexibility or stiffness [39]. However, this idea is certainly consistent with field observations made during the monarch migration, where wing condition (i.e., degree of damage and wear) of females has been found to be significantly better than those of males [9, 40]. In fact, Borland et al. [40] specifically noted that females with damaged wings were less frequently found than were males at fall tagging sites in Minnesota and Texas, which is in agreement with results of the current study showing females have thicker (and presumably sturdier) wings.

Other results found here were not as surprising. Male monarchs tended to be larger overall than females, which is consistent with multiple prior studies $[8,11,13,14,40,41]$. It is worth noting that individual size itself can also be an important trait for successful migration. Monarchs from migratory populations tend to be larger than nonmigratory populations $[13,42]$. Larger wings would provide greater surface areas for soaring flight, which monarchs utilize during migration [43-45], presumably to save energy [46]. Other evidence for the importance of size comes from observations within the migration period; multiple independent studies have found that late-migrating monarchs tend to be small $[11,40,47,48]$, suggesting small size hinders migration progress.

In conclusion, with this investigation into flight-related morphology of monarch butterflies we discovered that male and female monarchs differ in certain key traits; that is, females tend to have lower wing loading than males, and females also had relatively thicker wings. This last result could be interpreted as a sign of higher tensile strength in female wings, which is supported by field observations of greater wing condition in migrating females. Both results help to explain the apparent higher migratory success rates of female monarchs in the eastern North American population. Collectively, these data add to the exceptional wealth of knowledge around the monarch butterfly and still highlight the many gaps that remain in our knowledge of this, the most famous of butterflies.

\section{Conflict of Interests}

The authors declare that there is no conflict of interests regarding the publication of this paper.

\section{Acknowledgments}

The authors thank Sonia Altizer for the use of lab space and equipment during this project. They are also grateful to Jaap de Roode, for the use of monarch specimens. The paper was improved after helpful comments by Daniel Hanley.

\section{References}

[1] L. P. Brower, "Understanding and misunderstanding the migration of the monarch butterfly (Nymphalidae) in North America: 1857-1995," Journal of the Lepidopterists' Society, vol. 49, no. 4, pp. 304-385, 1995.

[2] L. P. Brower, "Monarch butterfly orientation: missing pieces of a magnificent puzzle," Journal of Experimental Biology, vol. 199, no. 1, pp. 93-103, 1996.

[3] K. Berwaerts, H. Van Dyck, and P. Aerts, "Does flight morphology relate to flight performance? An experimental test with the butterfly Pararge aegeria," Functional Ecology, vol. 16, no. 4, pp. 484-491, 2002.

[4] M. Almbro and C. Kullberg, "Impaired escape flight ability in butterflies due to low flight muscle ratio prior to hibernation," Journal of Experimental Biology, vol. 211, no. 1, pp. 24-28, 2008.

[5] K. Berwaerts and H. Van Dyck, "Take-off performance under optimal and suboptimal thermal conditions in the butterfly Pararge aegeria," Oecologia, vol. 141, no. 3, pp. 536-545, 2004.

[6] A. K. Davis, J. Chi, C. Bradley, and S. Altizer, “The redder the better: wing color predicts flight performance in monarch butterflies," PLoS ONE, vol. 7, no. 7, Article ID e41323, 2012.

[7] G. Steffy, "Trends observed in fall migrant monarch butterflies (Lepidoptera: Nymphalidae) east of the Appalachian Mountains 
at an inland stopover in southern Pennsylvania over an eighteen year period," Annals of the Entomological Society of America, vol. 108, no. 5, pp. 718-728, 2015.

[8] L. J. Brindza, L. P. Brower, A. K. Davis, and T. Van Hook, "Comparative success of monarch butterfly migration to overwintering sites in Mexico from inland and coastal sites in Virginia," Journal of the Lepidopterists' Society, vol. 62, no. 4, pp. 189-200, 2008.

[9] J. W. McCord and A. K. Davis, "Characteristics of monarch butterflies (Danaus plexippus) that stopover at a site in coastal South Carolina during fall migration," The Journal of Research on the Lepidoptera, vol. 45, pp. 1-8, 2012.

[10] A. K. Davis and E. Rendón-Salinas, "Are female monarch butterflies declining in eastern North America? Evidence of a 30 -year change in sex ratios at Mexican overwintering sites," Biology Letters, vol. 6, no. 1, pp. 45-47, 2010.

[11] J. W. McCord and A. K. Davis, "Biological observations of monarch butterfly behavior at a migratory stopover site: results from a long-term tagging study in coastal South Carolina," Journal of Insect Behavior, vol. 23, no. 6, pp. 405-418, 2010.

[12] D. Hanley, N. G. Miller, D. T. T. Flockhart, and D. R. Norris, "Forewing pigmentation predicts migration distance in wildcaught migratory monarch butterflies," Behavioral Ecology, vol. 24, no. 5, pp. 1108-1113, 2013.

[13] S. Altizer and A. K. Davis, "Populations of monarch butterflies with different migratory behaviors show divergence in wing morphology," Evolution, vol. 64, no. 4, pp. 1018-1028, 2010.

[14] L. P. Brower, L. S. Fink, and P. Walford, "Fueling the fall migration of the monarch butterfly," Integrative and Comparative Biology, vol. 46, no. 6, pp. 1123-1142, 2006.

[15] D. A. Satterfield, A. E. Wright, and S. Altizer, "Lipid reserves and immune defense in healthy and diseased migrating monarchs Danaus plexippus," Current Zoology, vol. 59, no. 3, pp. 393-402, 2013.

[16] J. J. Brown and G. M. Chippendale, "Migration of the monarch butterfly, Danaus plexippus: energy sources," Journal of Insect Physiology, vol. 20, no. 7, pp. 1117-1130, 1974.

[17] J. C. de Roode, L. R. Gold, and S. Altizer, "Virulence determinants in a natural butterfly-parasite system," Parasitology, vol. 134, no. 5, pp. 657-668, 2007.

[18] J. C. de Roode, J. Chi, R. M. Rarick, and S. Altizer, "Strength in numbers: high parasite burdens increase transmission of a protozoan parasite of monarch butterflies (Danaus plexippus)," Oecologia, vol. 161, no. 1, pp. 67-75, 2009.

[19] J. C. de Roode, A. J. Yates, and S. Altizer, "Virulencetransmission trade-offs and population divergence in virulence in a naturally occurring butterfly parasite," Proceedings of the National Academy of Sciences of the United States of America, vol. 105, no. 21, pp. 7489-7494, 2008.

[20] A. K. Davis, N. Cope, A. Smith, and M. J. Solensky, "Wing color predicts future mating success in male monarch butterflies," Annals of the Entomological Society of America, vol. 100, no. 2, pp. 339-344, 2007.

[21] A. K. Davis, B. Farrey, and S. Altizer, "Quantifying monarch butterfly larval pigmentation using digital image analysis," Entomologia Experimentalis et Applicata, vol. 113, no. 2, pp. 145147, 2004.

[22] A. K. Davis, B. D. Farrey, and S. Altizer, "Variation in thermally induced melanism in monarch butterflies (Lepidoptera: Nymphalidae) from three North American populations," Journal of Thermal Biology, vol. 30, no. 5, pp. 410-421, 2005.
[23] R. J. Wensler, "The ultrastructure of the indirect flight muscles of the monarch butterfly, Danaus plexippus (L.) with implications for fuel utilization," Acta Zoologica, vol. 58, no. 3, pp. 157-167, 1977.

[24] J. K. Hill, C. D. Thomas, and O. T. Lewis, "Flight morphology in fragmented populations of a rare British butterfly, Hesperia comma," Biological Conservation, vol. 87, no. 3, pp. 277-283, 1999.

[25] U. Norberg and O. Leimar, "Spatial and temporal variation in flight morphology in the butterfly Melitaea cinxia (Lepidoptera: Nymphalidae)," Biological Journal of the Linnean Society, vol. 77, no. 4, pp. 445-453, 2002.

[26] J. G. Kingsolver and R. B. Srygley, "Experimental analyses of body size, flight and survival in pierid butterflies," Evolutionary Ecology Research, vol. 2, no. 5, pp. 593-612, 2000.

[27] R. Dudley and R. B. Srygley, "Flight physiology of neotropical butterflies: allometry of airspeeds during natural free flight," Journal of Experimental Biology, vol. 191, pp. 125-139, 1994.

[28] S. J. Steppan, "Flexural stiffness patterns of butterfly wings (Papilionidea)," The Journal of Research on the Lepidoptera, vol. 35, pp. 61-77, 2000.

[29] D. N. Byrne, S. L. Buchmann, and H. G. Spangler, "Relationship between wing loading, wingbeat frequency and body-mass in homopterous insects," Journal of Experimental Biology, vol. 135, pp. 9-23, 1988.

[30] L. Svard and C. Wiklund, "Prolonged mating in the monarch butterfly Danaus plexippus and nightfall as a cue for sperm transfer," Oikos, vol. 51, no. 3, pp. 351-354, 1988.

[31] M. Almbro and C. Kullberg, "The downfall of mating: the effect of mate-carrying and flight muscle ratio on the escape ability of a pierid butterfly," Behavioral Ecology and Sociobiology, vol. 63, no. 3, pp. 413-420, 2009.

[32] R. Dudley, "Biomechanics of flight in neotropical butterflies: aerodynamics and mechanical power requirements," Journal of Experimental Biology, vol. 159, pp. 335-357, 1991.

[33] J. T. Vance and S. P. Roberts, "The effects of artificial wing wear on the flight capacity of the honey bee Apis mellifera," Journal of Insect Physiology, vol. 65, pp. 27-36, 2014.

[34] M. Almbro and C. Kullberg, "Weight loading and reproductive status affect the flight performance of Pieris napi butterflies," Journal of Insect Behavior, vol. 25, no. 5, pp. 441-452, 2012.

[35] T. W. Sappington and C. S. Burks, "Patterns of flight behavior and capacity of unmated navel orangeworm (Lepidoptera: Pyralidae) adults related to age, gender, and wing size," Environmental Entomology, vol. 43, no. 3, pp. 696-705, 2014.

[36] D. J. Kemp, "Sexual selection and morphological design: the tale of two territorial butterflies," Australian Journal of Zoology, vol. 58, no. 5, pp. 289-294, 2010.

[37] C. J. Breuker, P. M. Brakefield, and M. Gibbs, "The association between wing morphology and dispersal is sex-specific in the glanville fritillary butterfly Melitae cinxia (Lepidoptera: Nymphalidae)," European Journal of Entomology, vol. 104, no. 3, pp. 445-452, 2007.

[38] T. Merckx, B. Karlsson, and H. Van Dyck, "Sex- and landscaperelated differences in flight ability under suboptimal temperatures in a woodland butterfly," Functional Ecology, vol. 20, no. 3, pp. 436-441, 2006.

[39] S. A. Combes and T. L. Daniel, "Flexural stiffness in insect wings I. Scaling and the influence of wing venation," Journal of Experimental Biology, vol. 206, no. 17, pp. 2979-2987, 2003. 
[40] J. Borland, C. C. Johnson, T. W. Crumpton III, M. Thomas, S. Altizer, and K. Oberhauser, "Characteristics of fall migratory monarch butterflies, Danaus plexippus, in Minnesota and Texas," in The Monarch Butterfly, Biology and Conservation, K. Oberhauser and M. Solensky, Eds., pp. 97-104, Cornell University Press, Ithaca, NY, USA, 2004.

[41] W. S. Herman, "Body weight and wing length changes in Minnesota populations of the monarch butterfly, Journal of the Lepidopterists' Society, vol. 42, no. 1, pp. 32-36, 1988.

[42] C. Dockx, "Directional and stabilizing selection on wing size and shape in migrant and resident monarch butterflies, Danaus plexippus (L.), in Cuba," Biological Journal of the Linnean Society, vol. 92, no. 4, pp. 605-616, 2007.

[43] F. A. Urquhart, The Monarch Butterfly: International Traveler, University of Toronto Press, Toronto, Canada, 1987.

[44] K. Schmidt-Koenig, "Migration strategies of monarch butterflies," in Migration: Mechanisms and Adaptive Significance, M. A. Rankin, Ed., vol. 27 of Contributions in Marine Science, pp. 786-798, The University of Texas at Austin, Austin, Tex, USA, 1985.

[45] D. L. Gibo, "Flight strategies of migrating monarch butterflies (Danaus plexippus L.) in Southern Ontario," in Insect Flight: Dispersal and Migration, W. Danthanarayana, Ed., Proceedings in Life Sciences, pp. 172-184, Springer, Berlin, Germany, 1986.

[46] D. L. Gibo and M. J. Pallett, "Soaring flight of monarch butterflies, Danaus plexippus (Lepidoptera: Danaidae), during the late summer migration in southern Ontario," Canadian Journal of Zoology, vol. 57, no. 7, pp. 1393-1401, 1979.

[47] D. L. Gibo and J. A. McCurdy, "Lipid accumulation by monarch butterflies (Danaus plexippus L.)," Canadian Journal of Zoology, vol. 71, no. 1, pp. 76-82, 1993.

[48] D. A. Satterfield and A. K. Davis, "Variation in wing characteristics of monarch butterflies during migration: earlier migrants have redder and more elongated wings," Animal Migration, vol. 2, pp. 1-7, 2014. 

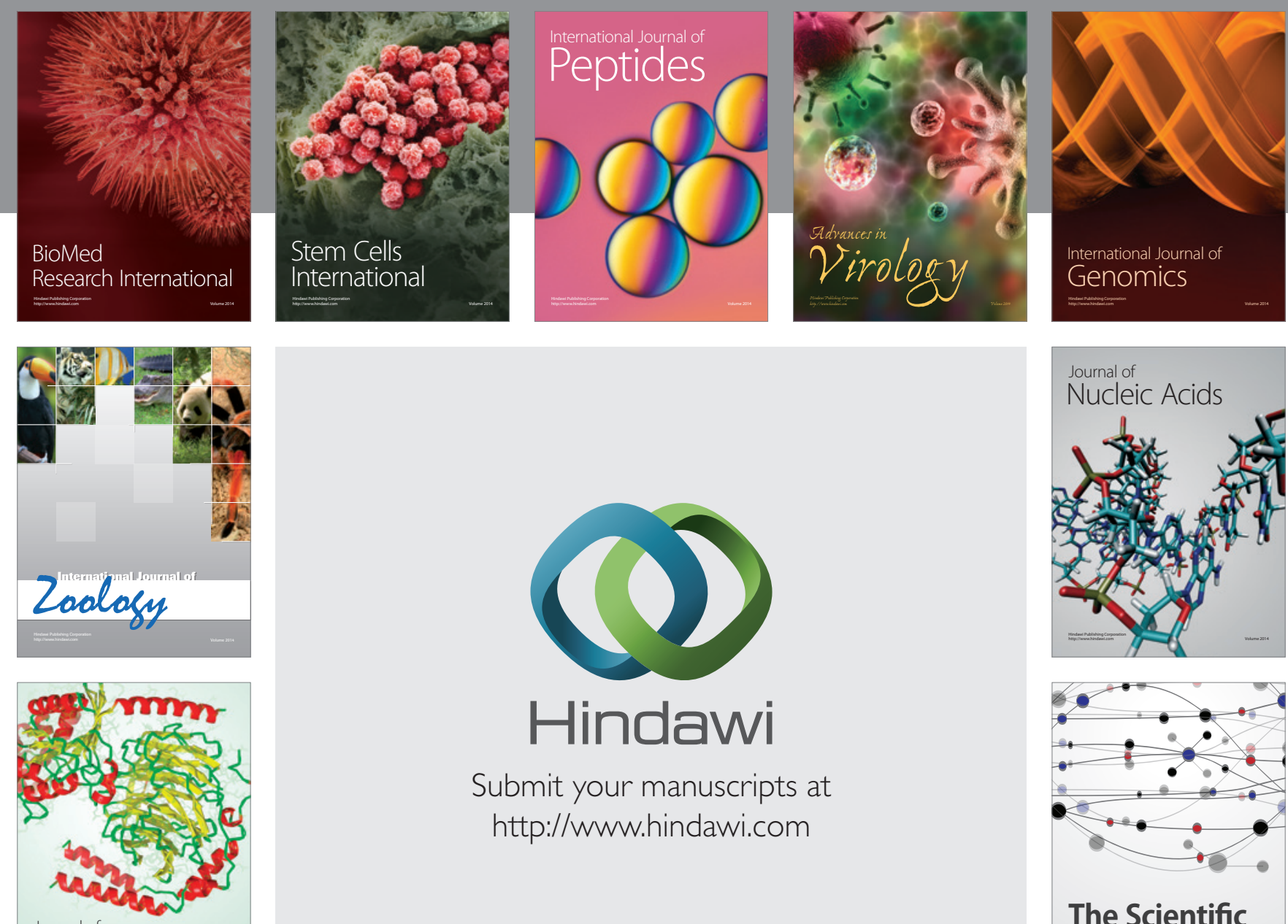

Submit your manuscripts at

http://www.hindawi.com

Journal of
Signal Transduction
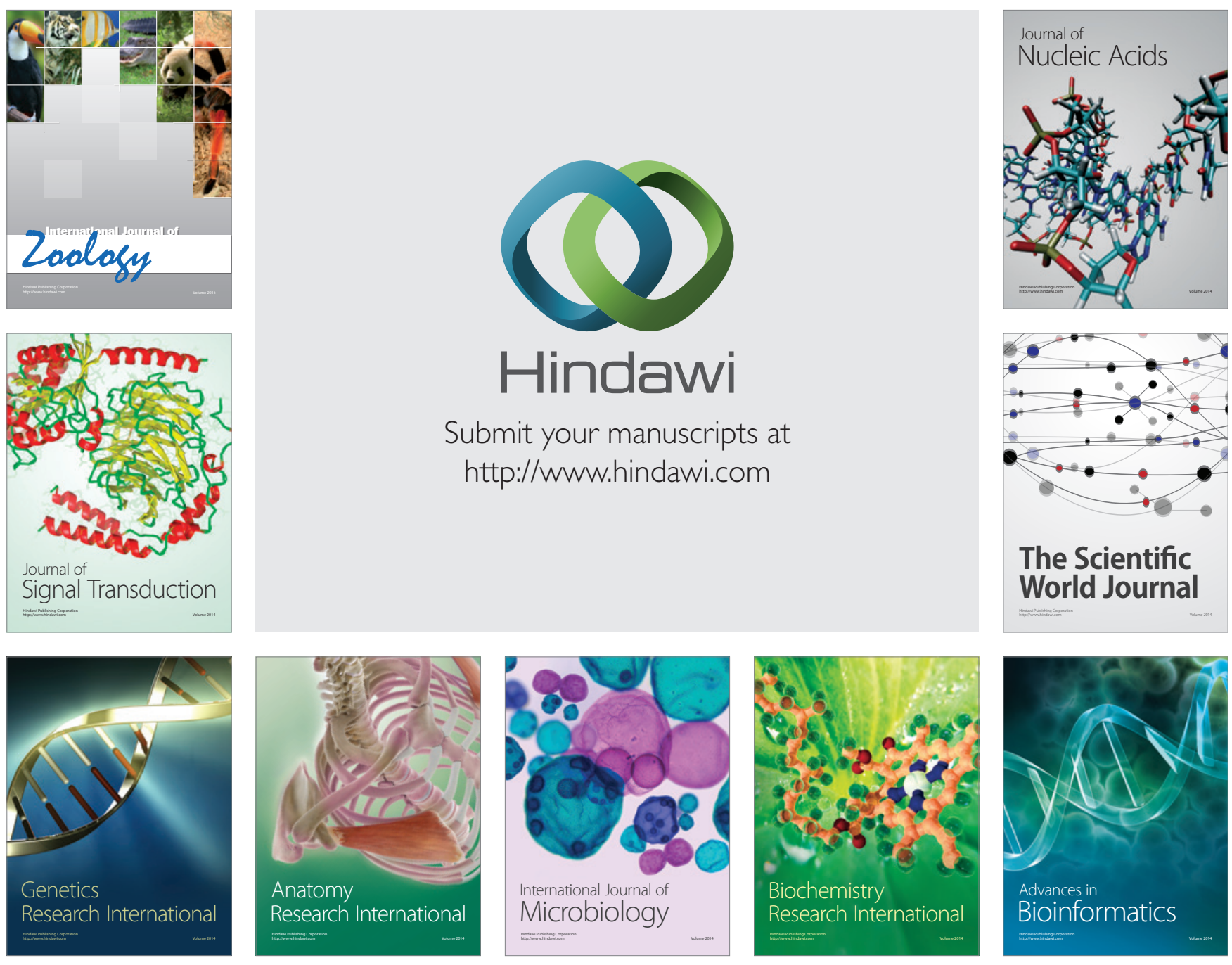

The Scientific World Journal
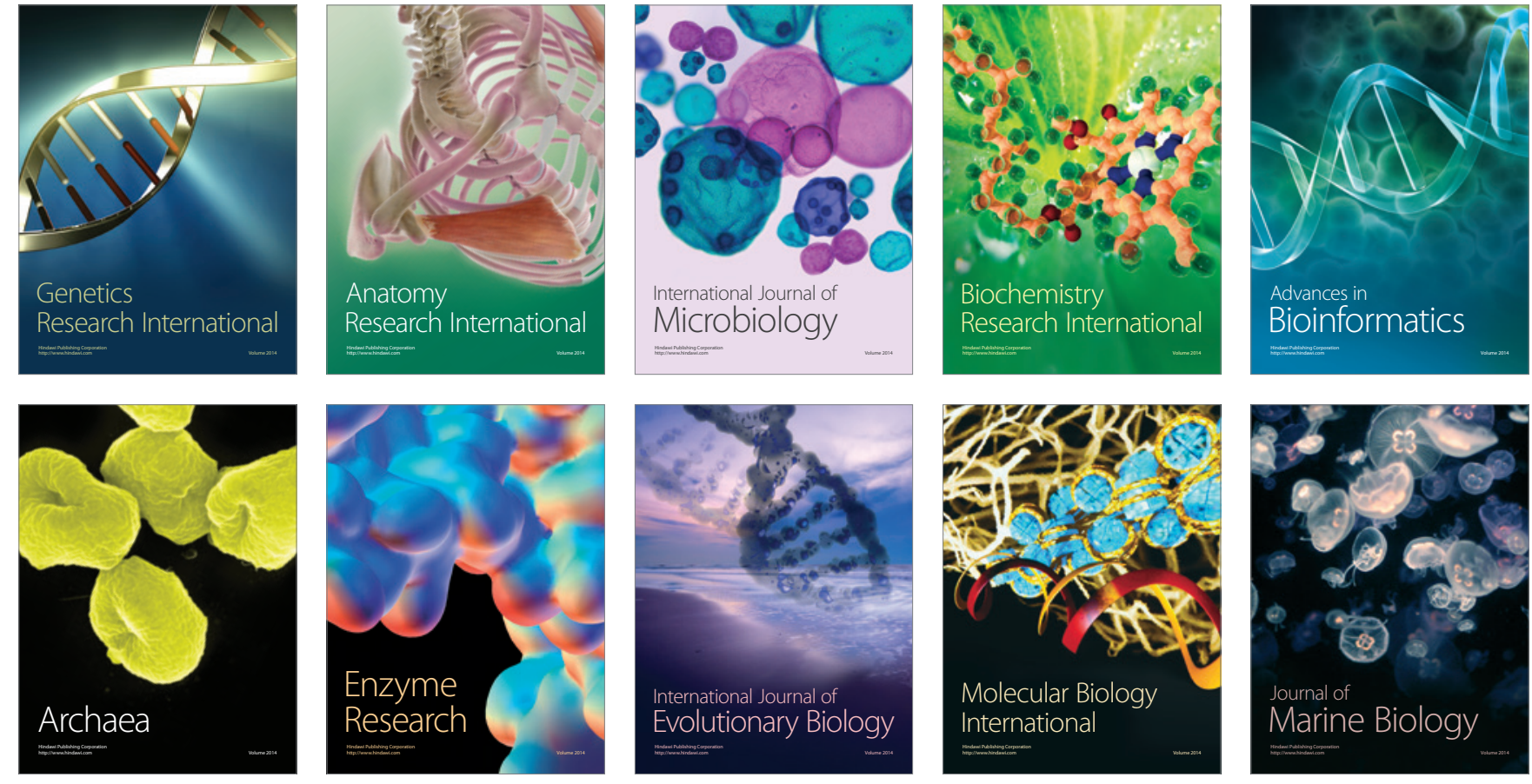